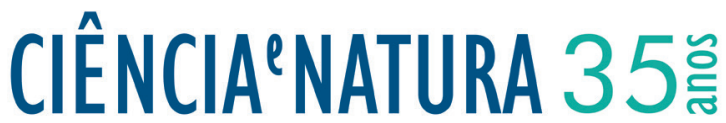

\section{Identificação das áreas de risco geomorfológico na microbacia hidrográfica Chácara das Flores, Santa Maria/RS.}

\author{
Identification of geomorphological risk areas in the watershed Chácara das Flores, \\ Santa Maria / RS.
}

\author{
Franciele da Silva ${ }^{1}$, Eliane Maria Foleto ${ }^{2}$ \\ ${ }^{1}$ Pós-graduanda em geografia, Universidade Federal de Santa Maria, Santa Maria, Brasil \\ ${ }^{2}$ Doutora, Departamento de Geociências, Universidade Federal de Santa Maria, Santa Maria, Brasil
}

\begin{abstract}
Resumo
A intensificação dos processos de urbanização aliada ao incremento populacional eà ocupação desordenada do espaço urbano promovem impactos ao sistema natural, desencadeando conflitos ambientais e situações de desequilíbrio entre o meio natural e a ocupação humana. Sob essa perspectiva o trabalho possui por objetivo o zoneamento e a hierarquização das áreas de risco geomorfológico da microbacia hidrográfica Chácara das Flores, localizada em Santa Maria/RS. A metodologia utilizada foi de Oliveira et al (2004) juntamente com a de Egler (1996), assim permitiu-se o cruzamento das variáveis ambientais consideradas (declividade, geologia, rede hidrográfica) para a identificação da susceptibilidade natural, com o Padrão Urbano da área e a ocorrência de eventos/acidentes, possibilitando identificar quatros situações de risco: iminente, alto, médio e baixo. Dentre os resultados encontrados, destaca-se os processos de dinâmica superficial relacionados a dinâmica fluvial como predominantes no local, já os processos vinculados à dinâmica das vertentes provocam riscos em menor proporção no local estudado. Os riscos mais comuns são as inundações/alagamentos e as erosões de margens. Estes eventos acontecem em função das ocupações desordenadas ao longo da área da rede de drenagem. Destaca-se aqui a importância de estudos como este no planejamento territorial, voltados principalmente à democratização dos espaços dentro da cidade.
\end{abstract}

Palavras-chave: Área de Risco, Geomorfologia, Microbacia Hidrográfica, Chácara das Flores, Santa Maria.

\begin{abstract}
The intensification of urbanization processes coupled with population growth and unplanned occupation of urban space promotes impacts to the natural system, triggering environmental conflict and imbalance between nature and human settlement. From this perspective the work has the objective of zoning and prioritization of geomorphologic risk areas in the watershed Chácara das Flores, located in Santa Maria/RS. The methodology used was de Oliveira et al (2004) together with that of Egler (1996) and allowed the crossing of the environmental variables considered (slope, geology, hydrographic) to identify the natural susceptibility, with the urban pattern area and the occurrence of events/accidents, possible to identify four risk situations: imminent, high, medium and low. Among the findings highlights the processes of surface dynamics related to fluvial dynamics as prevalent on site, since the linked processes to the dynamics of strands cause risks to a lesser extent in the studied area. The most common risks are flooding/inundation and erosion of margins. These events happen on the basis of disordered occupations along the area of the drainage. Here we highlight the importance of studies like this in territorial planning, mainly aimed at democratization of the spaces within the city.
\end{abstract}

Keywords: Risk Area, Geomorphology, Watershed, Chácara das Flores, Santa Maria. 


\section{Introdução}

A intensificação dos processos de urbanização e industrialização aliados ao incremento populacional promovem maiores impactos ao sistema natural. Essa situação se torna mais sensível quando vinculada diretamente às áreas urbanas, onde a concentração populacional e a demanda por infraestrutura são crescentes. Na maioria dos casos, sobretudo nos países em desenvolvimento, como o Brasil, a expansão urbana ocorre de modo desordenado, sem planejamento, desencadeando conflitos ambientais e situações de desequilíbrio entre o meio natural e a ocupação humana.

Associado a essa situação de desequilíbrios e conflitos ambientais está, na maioria dos casos, parte da sociedade que não dispõem de meios suficientes para obter um lugar seguro para sobreviver na cidade, deste modo, vê-se obrigada a residir em áreas potencialmente frágeis, como planícies de inundação, áreas deprimidas e vertentes íngremes, pois é necessário encontrar um lugar onde se possa morar para dar continuidade às atividades da vida cotidiana, mesmo que estes locais não sejam apropriados, acarretando em uma situação de risco para a população.

Julião et al. (2009) define o risco como a probabilidade de ocorrência de um processo e a respectiva estimativa das suas consequências sobre pessoas, bens ou ambiente, expressas em danos corporais e/ou prejuízos materiais e funcionais, diretos ou indiretos.

Egler (1996), Cerri [s.d.] e Amaral (1988) consideram a classe maior do conceito de risco sendo representada pelo risco ambiental, que resulta em três categorias ou classes básicas: riscos naturais, riscos tecnológicos e riscos sociais.

Mais especificamente, neste trabalho a tipologia adotada é a desenvolvida por Egler (1996), o qual associa o conceito de risco natural ao comportamento dos sistemas, associando os eventos que ocorrem naturalmente e que, devido à ocupação inadequada de certos espaços, acarreta em riscos à população.

Egler (1996) considera o grau de estabilidade e de instabilidade expresso em determinada área a eventos de curta ou longa duração, tais como inundações, desabamentos e aceleração de processos erosivos, eventos estes que foram analisados na área da microbacia Chácara das Flores. Tornando, assim, a denominação que mais se enquadra ao trabalho.

Rebelo (2003) consolida essa perspectiva de uso do conceito de rico natural, uma vez que engloba os riscos geomorfológicos à tipologia de riscos naturais. Os riscos geomorfológicos, descritos pelo autor, consistem na análise da dinâmica superficial do relevo e na observância de processos como ravinamento, movimentações de massa, desabamento ou deslizamento, inundações, entre outros. $\mathrm{O}$ autor também considera aspectos como inclinação das vertentes e áreas de margens dos rios.

As dinâmicas superficiais do relevo englobam os processos que ocorrem em áreas, principalmente, de declividades acentuadas - dinâmica das vertentes - e em áreas sujeitas às condicionantes dos canais de drenagem - dinâmica fluvial.

No que tange a dinâmica fluvial, os processos que foram analisados são aqueles relacionados com o escoamento superficial e seu impacto sobre a rede de drenagem urbana, em função de este processo natural originar uma série de fenômenos desencadeadores de risco, sendo as inundações/alagamentos os processos analisados.

O processo de inundação pode ser definido de uma forma mais ampla, de acordo com Castro (1998), como o transbordamento de água da calha normal de rios, mares, lagos e açudes, ou acumulação de água por drenagem deficiente, em áreas não habitualmente submersas.

Já os alagamentos são águas acumuladas nas ruas e nos perímetros urbanos por fortes precipitações pluviométricas, em cidades com sistemas de drenagem deficientes. Nos alagamentos, o extravasamento das águas depende muito mais de uma drenagem deficiente, que dificulta a vazão das águas acumuladas, do que das precipitações locais.

No que tange a dinâmica das vertentes, outro processo condicionado pela dinâmica superficial do relevo, Oliveira (2004, p. 5) subdivide em dois processos fundamentais: "A dinâmica das vertentes está associada aos processos de transporte de massa e aos movimentos de massa".

Por transporte de massa entende-se a ação da erosão atuando nas vertentes. É um processo natural, sua atuação após um longo período de tempo é responsável pelas modificações nas formas de relevo e, consequentemente, seu reflexo na paisagem.

Outro processo oriundo da dinâmica das vertentes são os movimentos de massa. Segundo Castro (1998, p. 28), os movimentos de massa consistem "em todo e qualquer movimento coletivo de materiais terrosos e/ou rochosos, independentemente da diversidade de processos, causas, velocidades, formas e demais características".

Estes processos, descritos quando se desenvolvem em ambientes onde a ação humana se encontra presente, podem ocasionar tanto grandes perdas econômicas como também vitimar as populações envolvidas. Infelizmente, esses fatos não são tão raros, perante as inúmeras tragédias relacionadas a enchentes e deslizamentos de terra que vem ocorrendo cada vez com maior frequência e intensidade, atingindo centenas de cidades, milhões de brasileiros e deixando um rastro de vítimas fatais, além de prejuízos econômicos. Perante este cenário é necessário fazer uma análise isenta e responsável sobre as ações a serem tomadas e que podem minimizar ou agravar a situação em caso de eventos climáticos extremos, seja no futuro imediato ou em um longo prazo.

Sob essa perspectiva, o trabalho possui como objetivo o zoneamento e a hierarquização das áreas de risco geomorfológico da microbacia hidrográfica Chácara das Flores, localizada na área urbana de Santa Maria/RS, 
abrangendo os bairros Chácara das Flores e Perpétuo Socorro. Apresentando, desta forma, mais um subsídio ao planejamento municipal isento e que tenha por objetivo a real democratização dos espaços da cidade.

\section{Procedimentos metodológicos}

O material cartográfico utilizado foi a base para todos os produtos cartográficos obtidos neste trabalho e consistem na carta topográfica de Santa Maria - SE em escala 1:25.000; a Carta Geotécnica de Santa Maria em escala 1:25.000, confeccionada por Maciel Filho (1990) e imagem do satélite LANDSAT 7. O software utilizado para o processamento dos mapas foi ArcGIS 9.3 (ESRI).

Para a identificação das áreas de risco geomorfológico, foi feita uma adaptação da metodologia proposta por Egler (1996), combinada com a metodologia proposta por Oliveira et. al (2004), combinando os mapas de Susceptibilidade Natural, Padrão Urbano e Eventos/Acidentes.

Para estabelecer as áreas naturalmente susceptíveis a risco, foram consideradas a rede de drenagem, o substrato geológico e a declividade. Sendo assim, são consideradas susceptíveis as áreas que:

- Tenham declividade inferior a $2 \%$, as quais, por serem áreas muito planas, são susceptíveis a processos de inundações/alagamentos; Essas áreas são identificadas através do mapa de declividade do local;

- Apresentam declividades superiores a $12 \%$, onde os processos erosivos da vertente são mais acentuados, com necessidade de corte para a ocupação, sendo, portanto, sujeitas a processos de movimento de massa; Essas áreas são identificadas através do mapa de declividade da microbacia;

- Áreas que registram a presença de depósitos fluviais juntos às drenagens, as quais são consideradas como geotecnicamente instáveis por Maciel Filho (1990); Essas áreas são identificadas com base no mapa geotécnico da área de estudo;

Além da observância das seguintes condições:

- Áreas com distância inferior a 30 metros dos cursos fluviais, que por serem próximas ao leito são susceptíveis aos processos de inundação e solapamento das margens. A Lei Federal 6.766/79 estabelece as áreas junto aos canais como sendo "non aedificandi" e também, conforme o Código Florestal Brasileiro, a ocupação dessas áreas é vetada. Essas áreas foram identificadas considerando a rede de drenagem;

- Áreas onde foram evidenciados processos de dinâmica superficial em estágio intensificado pelas atividades antrópicas. Essas áreas foram identificadas em campo, coletadas as coordenadas geográficas de cada local e marcados os locais no mapa de susceptibilidade natural.

Para a confecção do mapa Padrão Função Urbana, foram consideradas as características construtivas/estruturais das moradias (padrão construtivo alto/médio/ baixo), as condições de infraestrutura básica oferecida à população residente na área (rede pluvial, canalização do esgoto cloacal e pluvial, bem como o adensamento populacional e a forma de ocupação do espaço - ordenada/desordenada).

Portanto, o Padrão Urbano de determinada área expressa a vulnerabilidade do sistema social que, em face a deflagração de um evento, pode vir a causar perdas econômicas e, até mesmo, humanas. A partir destes levantamentos, pode-se estabelecer o padrão urbano dividindo-se em Alto, Médio e Baixo Padrão Urbano. Para a hierarquização foram atribuídos valores de 0 e 1 para os parâmetros considerados de acordo com sua ocorrência, como pode ser observado no quadro 1 :

Quadro 1: Parâmetros utilizados para a definição do Padrão Urbano:

\begin{tabular}{|l|l|c|}
\hline \multirow{2}{*}{ Variável } & Característica & Valor \\
\hline \multirow{2}{*}{ Esgoto Viária } & Pavimentada & 0 \\
\cline { 2 - 3 } & Não Pavimentada & 1 \\
\hline \multirow{2}{*}{ Rede Pluvial } & Canalizado & 0 \\
\cline { 2 - 3 } & Direto no Ambiente & 1 \\
\hline \multirow{2}{*}{ Padrão Construtivo } & Apresenta & 0 \\
\cline { 2 - 3 } & Não Apresenta & 1 \\
\hline \multirow{2}{*}{ Ocupação } & Alto/Médio & 0 \\
\cline { 2 - 3 } & Baixo & 1 \\
\hline \multirow{2}{*}{ Obras de Contenção } & Organizada & 0 \\
\cline { 2 - 3 } & Desordenada & 1 \\
\cline { 2 - 3 } & Apresenta & 0 \\
\hline
\end{tabular}

Fonte: Oliveira et al. (2004). 
A partir da soma atribuída às características que apresentam os locais, pode-se estabelecer o padrão urbano, dividindo-se a área em: Alto, Médio e Baixo Padrão Função Urbana:

- Alto Padrão: constitui as áreas que apresentam valor máximo 6 na soma total dos atributos;

- Médio Padrão: constitui as áreas que apresentam soma igual a 3, 4 e 5;

- Baixo Padrão: áreas que tenham apresentado soma igual a 0,1 e 2 .

O registro de acidente é utilizado, na hierarquização do risco, como um fator agravante da situação de risco já instalada. A coleta de dados foi obtida através de dados dos órgãos públicos responsáveis, Defesa Civil e Corpo de Bombeiros, pesquisa em acervos de jornais, além da entrevista com os moradores das áreas de risco, onde se procura identificar o tipo e a extensão dos processos.

O grau de risco é o produto do cruzamento entre a susceptibilidade natural, o padrão urbano e a ocorrência de algum evento/acidente na área. O quadro 2 exemplifica o cruzamento das variáveis consideradas.

Desta forma foi possível estabelecer quatro graus para as áreas de risco:

Risco IV: quando a área ocupada com Alto Padrão apresenta susceptibilidade natural e não tem registro de ocorrência de eventos, constitui-se em uma área de grau IV, considerada de baixo risco;

Risco III: ocorre quando a área se apresenta com susceptibilidade natural e está ocupada com moradias de Médio Padrão Urbano sem ocorrência de eventos.

Quadro 2: Cruzamento das variáveis e respectivos graus de risco

\begin{tabular}{|l|l|l|l|}
\hline Padrão Urbano & Alto & Médio & Baixo \\
\hline Susceptibilidade Natural & Risco Baixo & Risco Moderado & Risco Alto \\
\hline $\begin{array}{l}\text { Ocorrência de } \\
\text { Eventos/Acidentes }\end{array}$ & Risco Moderado & Risco Alto & Risco Iminente \\
\hline
\end{tabular}

Org.: Silva, F. (2013).

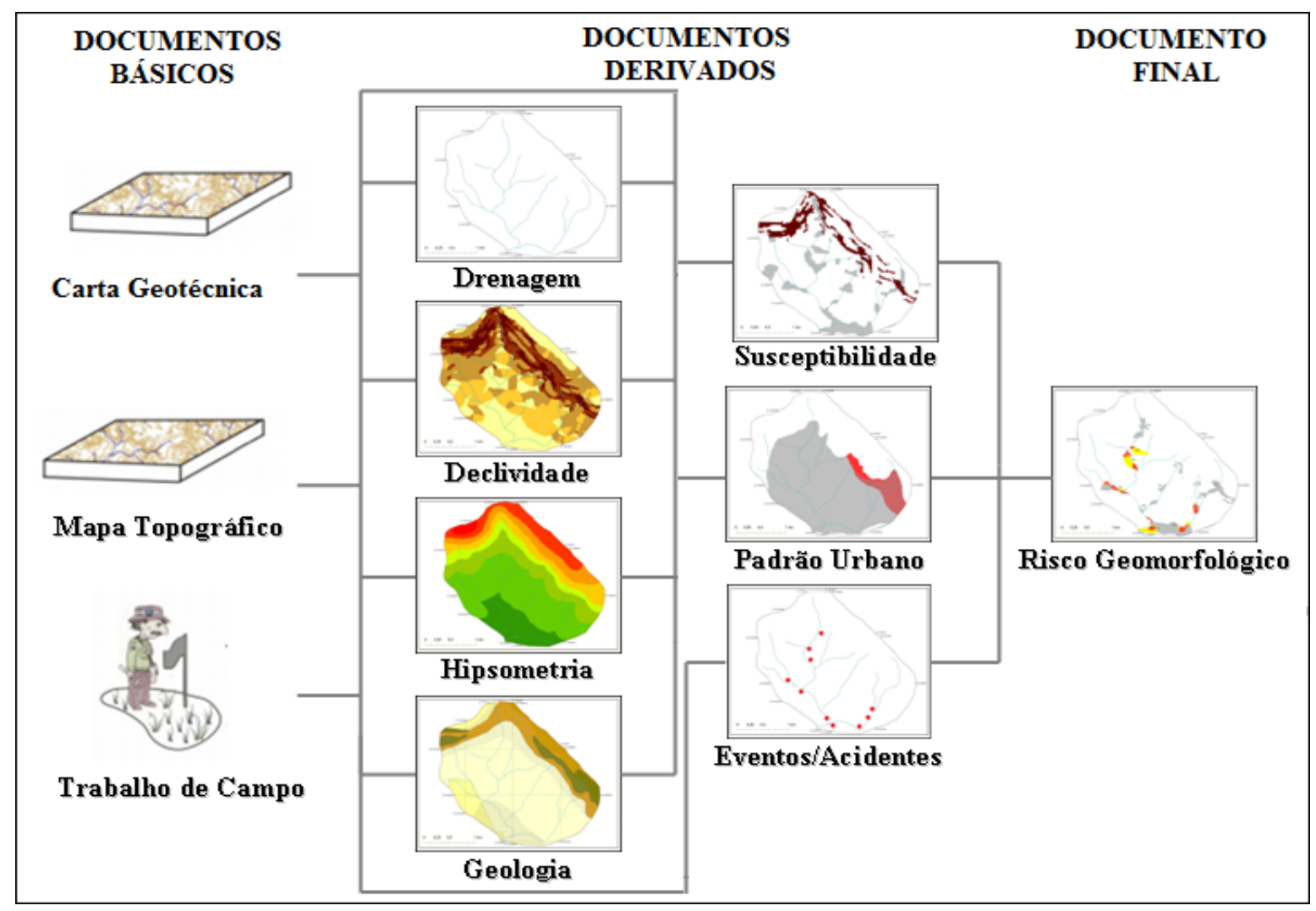

Figura 1: Combinação de mapas para obtenção do resultado final da pesquisa.

Elaboração e organização: SILVA, F. 
$\mathrm{Ou}$, ainda, se a área susceptível estiver ocupada por moradias de Alto Padrão Urbano com registro de ocorrências. Constituem áreas de risco moderado de grau III;

Risco II: quando a área susceptível apresentar predomínio de ocupação de Médio Padrão Urbano com registro de eventos ou, ainda, de baixo padrão sem registro de evento, constitui-se em áreas de alto risco de grau II;

Risco I: quando a área ocupada com moradias de Baixo Padrão Urbano apresentar susceptibilidade natural e ocorrência de eventos é considerada de risco iminente, recebendo grau I, onde a intervenção dos órgãos públicos responsáveis deve ser de curto prazo.

Na figura 01 pode-se observar a combinação de mapas que possibilitaram o resultado final da pesquisa:

\section{Resultados e discussões}

\subsection{Caracterização da área de estudo}

A microbacia hidrográfica Chácara das Flores está inserida na área urbana do município de Santa Maria/RS.

No que tange a área de estudo, a microbacia encontrase em área de transição topográfica e geomorfológica, com a presença do Rebordo do Planalto Meridional ao norte e o predomínio da Depressão Central na área mais próxima ao centro da cidade (porção sul da microbacia).

Quanto à cobertura vegetal, na porção norte da microbacia há o predomínio da Mata Atlântica, acompanhando as áreas do Rebordo do Planalto. No restante da microbacia, o que predomina é a urbanização, com áreas densamente ocupadas e pequena presença de ve- getação. Através da figura 2, podemos identificar, dentre outras características, a geomorfologia e a vegetação presente no local.

Os bairros que integram a área da microbacia hidrográfica, Chácara das Flores e Nossa Senhora do Perpétuo Socorro, recobrem uma área de 397,18 hectares e 115,38 hectares, respectivamente, da área da microbacia hidrográfica, como pode ser observado na figura 2 .

Ainda no que tange a área referente aos bairros, pode-se destacar a falta de infraestrutura, tanto de ruas pavimentadas quanto de saneamento básico, e descaso com o fim que é dado ao lixo domiciliar, principalmente na porção sul dos dois bairros, onde há a maior concentração populacional.

$\mathrm{Na}$ área da microbacia, as principais problemáticas ambientais identificadas são referentes à questão dos recursos hídricos, principalmente pelo fato de apresentarem grande quantidade de córregos na área, estando estes degradados e poluídos, com suas margens ocupadas por moradias, não se adequando à legislação ambiental, além do acúmulo de lixo nas margens do canal.

Pode-se perceber, também, ao longo da área intervenções nos canais, desde a proteção das margens com pedras soltas e pneus, além da canalização em alguns pontos e barramentos no decorrer do canal principal.

\subsection{As áreas de risco geomorfológico}

Através da combinação dos mapas de susceptibilidade natural, padrão urbano e eventos/acidente, foi possível elaborar o zoneamento e a hierarquização das áreas de risco geomorfológico na microbacia hidrográfica

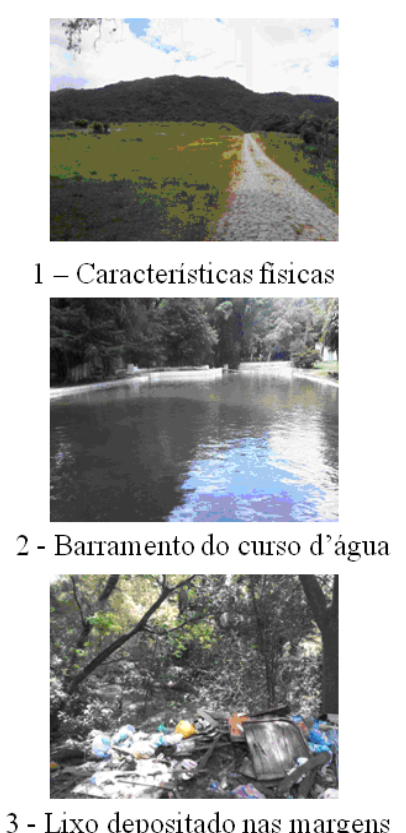

3 - Lixo depositado nas margens
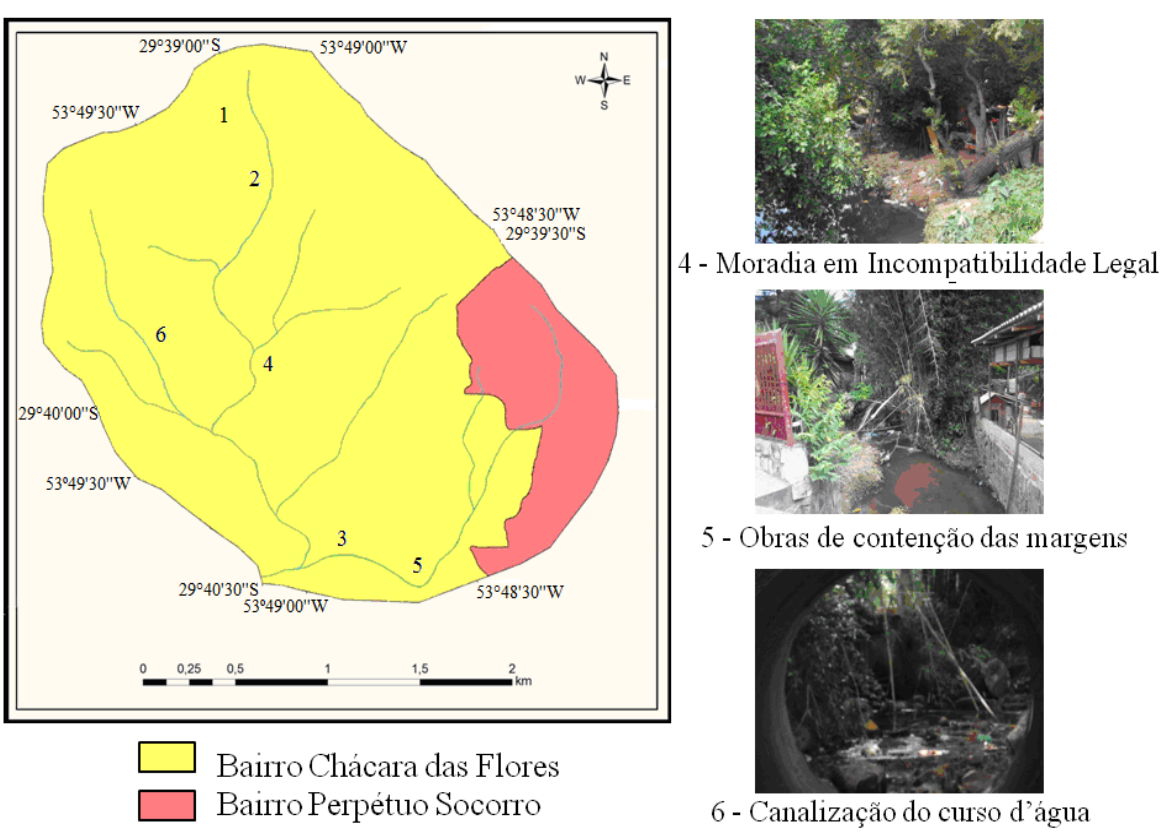

Figura 2 - Mapa da Microbacia Hidrográfica Chácara das Flores e algumas de suas principais características Elaboração e organização: SILVA, F. 
Chácara das Flores.

O estudo das propriedades do ambiente natural propicia um entendimento das potencialidades ou das restrições impostas para uma determinada área, principalmente quando o objetivo do uso é para fins de desenvolvimento urbano.

A análise conjunta do mapa de declividade e do mapa geotécnico possibilitou uma visão integrada desses aspectos relevantes para identificar as áreas que, se ocupadas, venham a desenvolver circunstâncias de risco, portanto são áreas susceptíveis, ou caso já estejam ocupadas, a interligação com o padrão urbano destas áreas e a ocorrência de eventos/acidentes possibilita o estabelecimento do grau de risco geomorfológico.

As áreas planas do relevo, representadas pelas planícies aluviais onde se encontram declividades inferiores a $2 \%$, são propícias, se ocupadas, a desenvolver processos de inundações/alagamentos. Maciel Filho (1990) estabelece essas áreas como geotecnicamente impróprias, juntamente com os depósitos fluviais. Por serem sedimentos quaternários inconsolidados, possuem extrema fragilidade aos processos erosivos, desencadeados pela vazão das águas do canal.
Agregada à situação geológica instável, pode-se destacar a problemática com o lixo na área da microbacia como um fator agravante, pois contribui com a obstrução dos bueiros e ocasiona o barramento de setores da rede de drenagem, facilitando, assim, o processo de alagamento dessas áreas com declividades inferiores a $2 \%$ e/ou das áreas geotecnicamente instáveis.

Nas áreas onde a energia do relevo é maior, tem-se outro processo da dinâmica superficial que, em áreas urbanas, causa alguns problemas quando desencadeado, a erosão.

Os locais onde estas áreas foram identificadas, apesar de susceptíveis, não possuem o agravante da falta de infraestrutura, pois são áreas onde reside a população mais abastada, com casas bem estruturadas e que possuem um bom padrão de infraestrutura.

Analisando o mapa de susceptibilidade (figura 3), podemos concluir que as áreas com maior susceptibilidade natural à dinâmica das vertentes localizam-se na porção norte e leste da microbacia. Essa área não é densamente ocupada, como nas outras porções da microbacia. Somado a isso, destacam-se as condições de infraestrutura dessas áreas, que lhes conferem uma

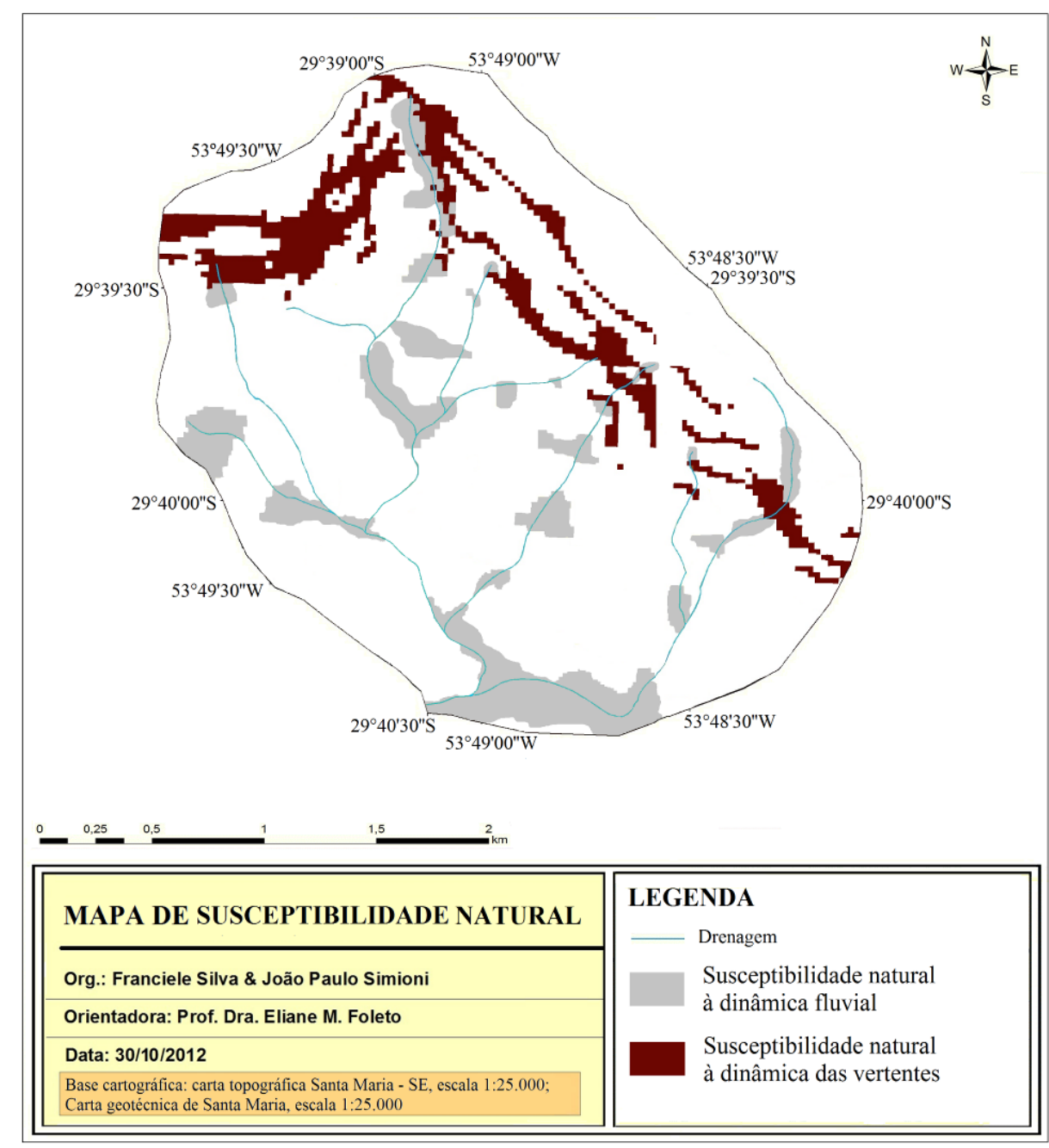

Figura 3: Mapa de susceptibilidade natural da microbacia hidrográfica Chácara das Flores. 
situação mais estável.

As declividades superiores a 45\% são encontradas nas colinas junto ao rebordo, sustentadas pelos sedimentos da Formação Caturrita. Esse substrato sedimentar friável, que recobre grande parte da microbacia, produz uma grande carga sedimentar que vai ser removida para a drenagem, também contribuindo para os processos de dinâmica fluvial.

Nessas áreas é indispensável a conservação da vegetação, pois, sendo uma área onde as declividades são elevadas, aliado ao substrato formado por rochas predominantemente sedimentares, constitui-se em área fonte de material sólido para a microbacia, acarretando em aumento dos processos de assoreamento do canal a jusante dessa área.

As áreas identificadas pela susceptibilidade natural à dinâmica fluvial são locais habitados, em geral, por uma população de renda mais baixa, a infraestrutura do local e das próprias residências são inferiores a porção norte da microbacia, além dos canais apresentarem grande quantidade de lixo acumulado, agravando, assim, o cenário da susceptibilidade. Essas áreas, com base no mapa geotécnico, estão concentradas junto aos canais de drenagem.

No que tange a identificação do padrão urbano da área, foi feita uma divisão do espaço urbano da microbacia em: alto, médio e baixo padrão urbano, pois, para se estabelecer as áreas de risco geomorfológico, torna-se indispensável o entendimento de como o espaço urbano está edificado. Cada padrão implicará em uma maior ou menor vulnerabilidade, em vista do desencadeamento de algum evento, expondo de forma diferenciada essas áreas a circunstancias de risco, que podem ser tanto de ordem material e econômica, como também na possibilidade de vitimar a população com perdas de vidas.

Através do mapa do padrão urbano (figura 4), podemos concluir que as áreas com o melhor padrão urbano estão localizadas no setor leste da microbacia. Segundo os moradores, essa área foi a última do bairro Chácara das Flores a ser habitada, é uma área de expansão urbana, cuja especulação imobiliária é intensa. $O$ padrão das residências é alto e a demanda por infraestrutura foi bem atendida.

Já o médio padrão, que circunda a área com alto padrão urbano, está situado, predominantemente, no bairro Perpétuo Socorro e apresenta estruturas heterogêneas,

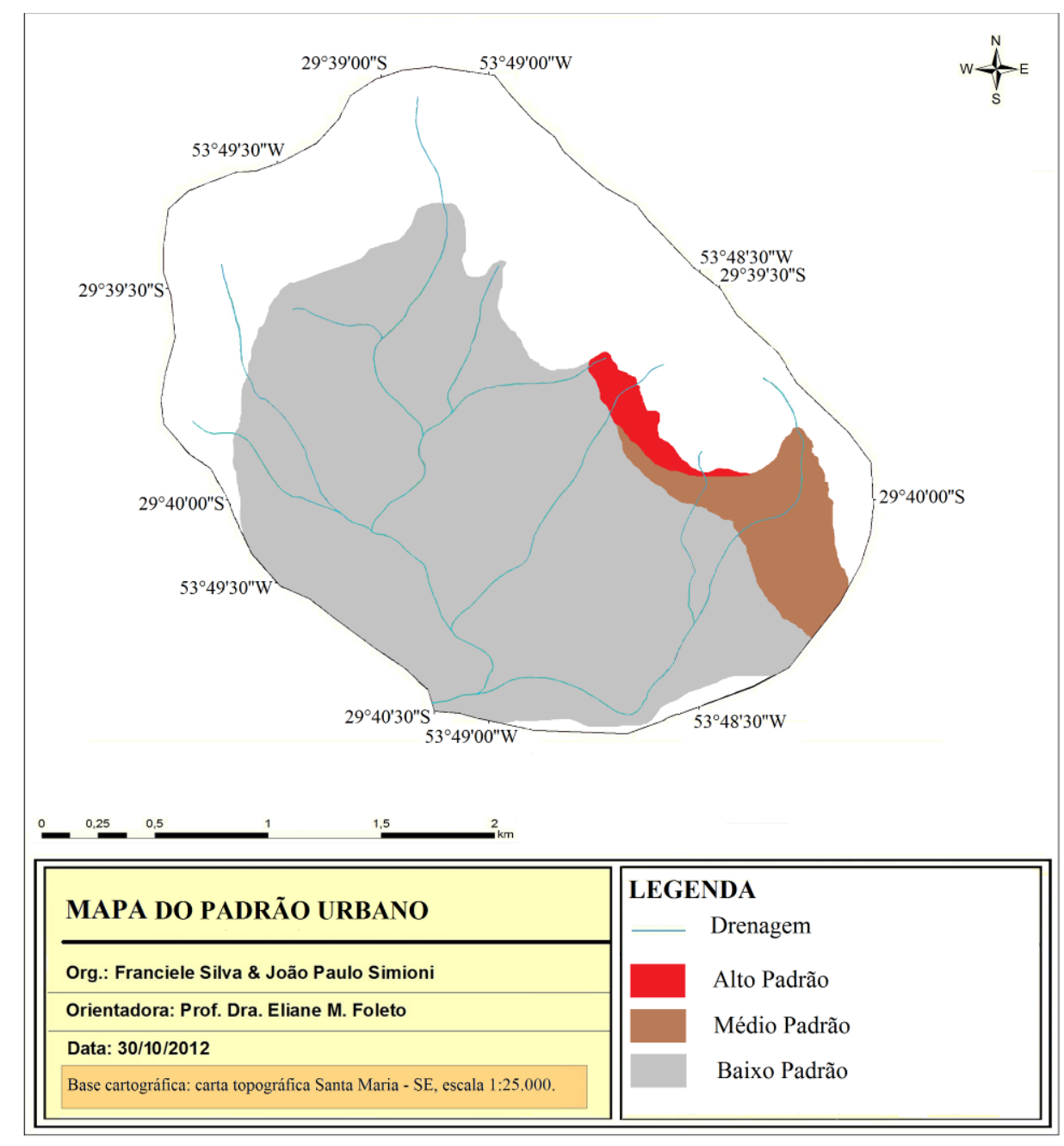

Figura 4: Mapa do Padrão Urbano da microbacia hidrográfica Chácara das Flores. 
com obras de infraestruturas, porém ainda deficientes. As moradias apresentam um padrão intermediário, com algumas exceções, e são caracterizadas, de maneira geral, com um bom padrão urbano.

Quanto às áreas de baixo padrão, essas ocupam mais da metade da área da microbacia. A falta de infraestrutura, tanto das residências, quanto das áreas públicas, é perceptível. $\mathrm{O}$ esgoto não é canalizado, as ruas não possuem pavimentação e as residências apresentam baixo padrão, além de muitas estarem sobre áreas de preservação permanente.

Para o estabelecimento das áreas de risco geomorfológico, houve a necessidade de obtenção da distribuição espacial dos eventos/acidentes ocorridos na microbacia.

Aqui utilizamos os termos evento e acidente associados, embora etimologicamente estes tenham significados diferentes. A formulação, feita por Cerri [s.d.] e Amaral (1998), conceitua o termo evento como algo acontecido, não sendo registradas consequências sociais e econômicas para a população envolvida, já o conceito de acidente evidencia um fato já ocorrido, que provocou perdas sociais e econômicas (perdas e danos).

Optou-se pela associação entre os termos pela dificul- dade encontrada em definir, entre os dados recolhidos, a distinção precisa entre um evento e um acidente, pois a fonte histórica encontrada para a obtenção dos dados foi os arquivos do jornal A Razão, que compreende os anos de 2005 a 2012, além das informações fornecidas pelos moradores quando da realização dos trabalhos de campo.

A figura 5, a seguir, corresponde ao mapa dos eventos/acidentes identificados na microbacia hidrográfica Chácara das Flores, tanto na pesquisa realizada junto aos arquivos do jornal A Razão, como também naqueles identificados nos trabalhos de campo. Os eventos/acidentes identificados estão relacionados com os movimentos de massa e erosão, assim como inundações e alagamentos.

A análise da distribuição dos eventos/acidentes nos permite observar que estão concentrados junto à rede de drenagem, em locais onde o padrão função urbana é baixo e a susceptibilidade natural é maior.

O número de eventos/acidentes tende a aumentar em uma relação direta com o aumento das áreas de margens ocupadas, uma vez que a ocupação destas áreas ocorre com a retirada da cobertura florestal, aumentando, assim, a probabilidade de ocorrência dos processos erosivos, pois

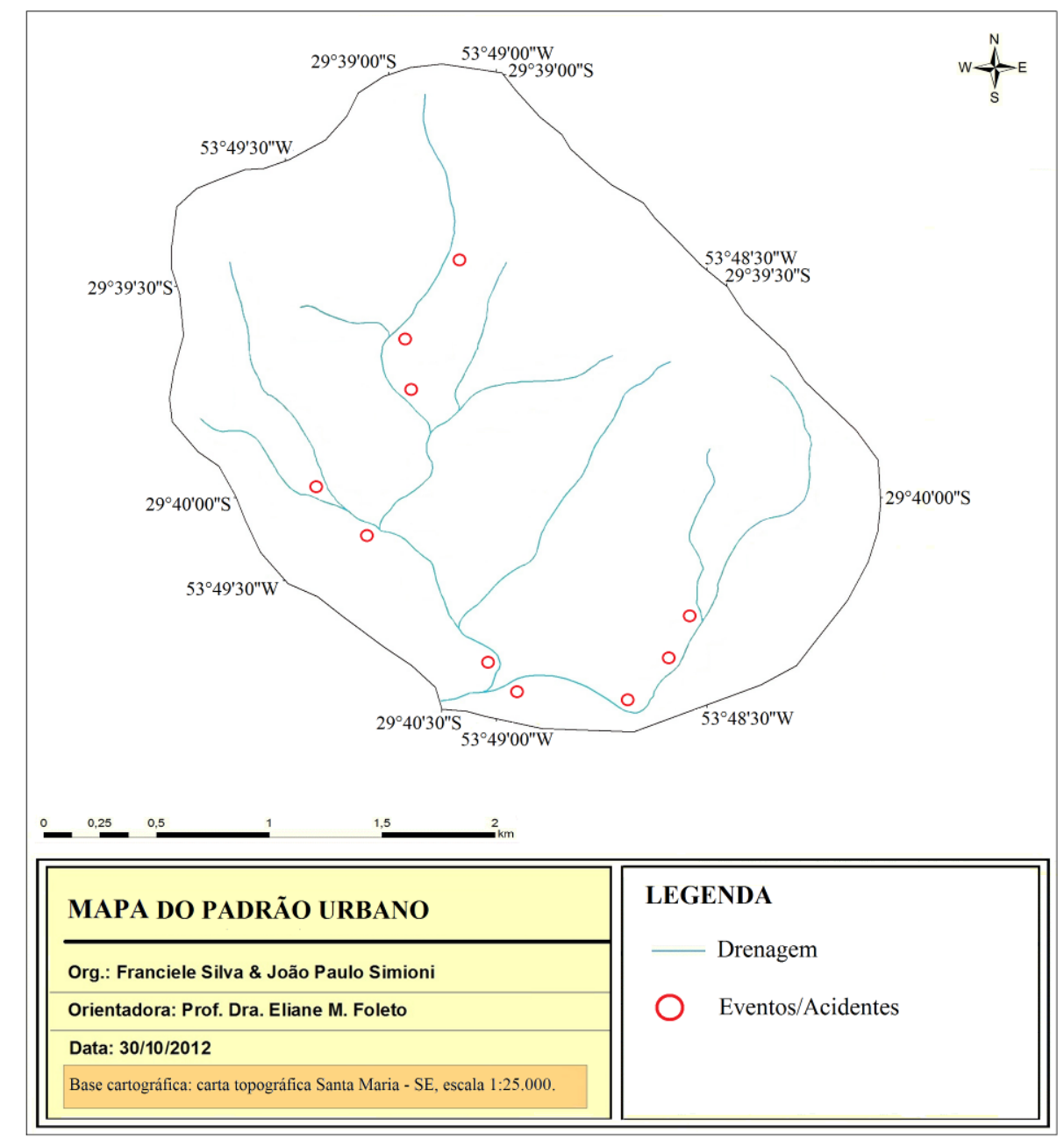

Figura 5: Mapa dos eventos/acidentes da microbacia hidrográfica Chácara das Flores. 
as áreas de margens ficam desprotegidas do carregamento de sedimentos pela rede de drenagem, caracterizando um possível cenário de risco geomorfológico.

As áreas de risco, hoje, representam um grave problema que muitas cidades brasileiras têm o dilema de enfrentar. Resultado de uma complexa interligação entre as propriedades naturais e as intervenções da sociedade, manifestam-se com maior intensidade nos grandes aglomerados urbanos, mas não sendo privilégio exclusivo destes, pois também ocorre o estabelecimento de áreas de risco nas pequenas e médias cidades, como pode ser exemplificado no caso da microbacia estudada.

Essas áreas de risco que são condicionadas pelas características ambientais, como relevo de planícies, que formam as áreas mais planas, onde as propriedades geotécnicas dos materiais são as de menor adequabilidade para uso urbano, ou relevos íngremes, onde a declividade do terreno constitui-se em um agravante para a edificação de moradias.

As áreas de risco, identificadas na microbacia Chácara das Flores, estão associadas, predominantemente, à dinâmica fluvial e, em menor proporção, à dinâmica das vertentes, esse resultado pode ser observado na figura 6:

Figura 6: Mapa das áreas de risco geomorfológico da microbacia hidrográfica Chácara das Flores.

Os processos geomorfológicos, vinculados à dinâmica das vertentes analisados e que se manifestam na microbacia hidrográfica Chácara das Flores, são a erosão e os movimentos de massa. Na área da microbacia, as áreas de risco, associadas aos processos erosivos, podem ser desencadeadas com maior facilidade sobre a formação sedimentar Caturrita, e são nessas áreas que predominou o risco associado à dinâmica das vertentes.

Essas áreas estão localizadas em setores onde a declividade é maior, na porção norte e leste da microbacia. Como visto no decorrer do trabalho, essas áreas apresentam um bom suporte de infraestrutura, tanto pública quanto das residências, viabilizando assim uma maior segurança no local. Todavia, o alto padrão urbano não exclui o risco do local, apenas o torna menos possível. Nessas áreas não foram identificados registros de acidentes, todavia a susceptibilidade ocorre, caracterizando áreas de grau de risco IV, na maioria das ocorrências.

Já os movimentos de massa são processos evidenciados com menor amplitude dentro da microbacia, basicamente em função das áreas com maior declividade, hoje, ainda não se constituírem em áreas densamente ocupadas, mas que em face da dinâmica urbana tendem

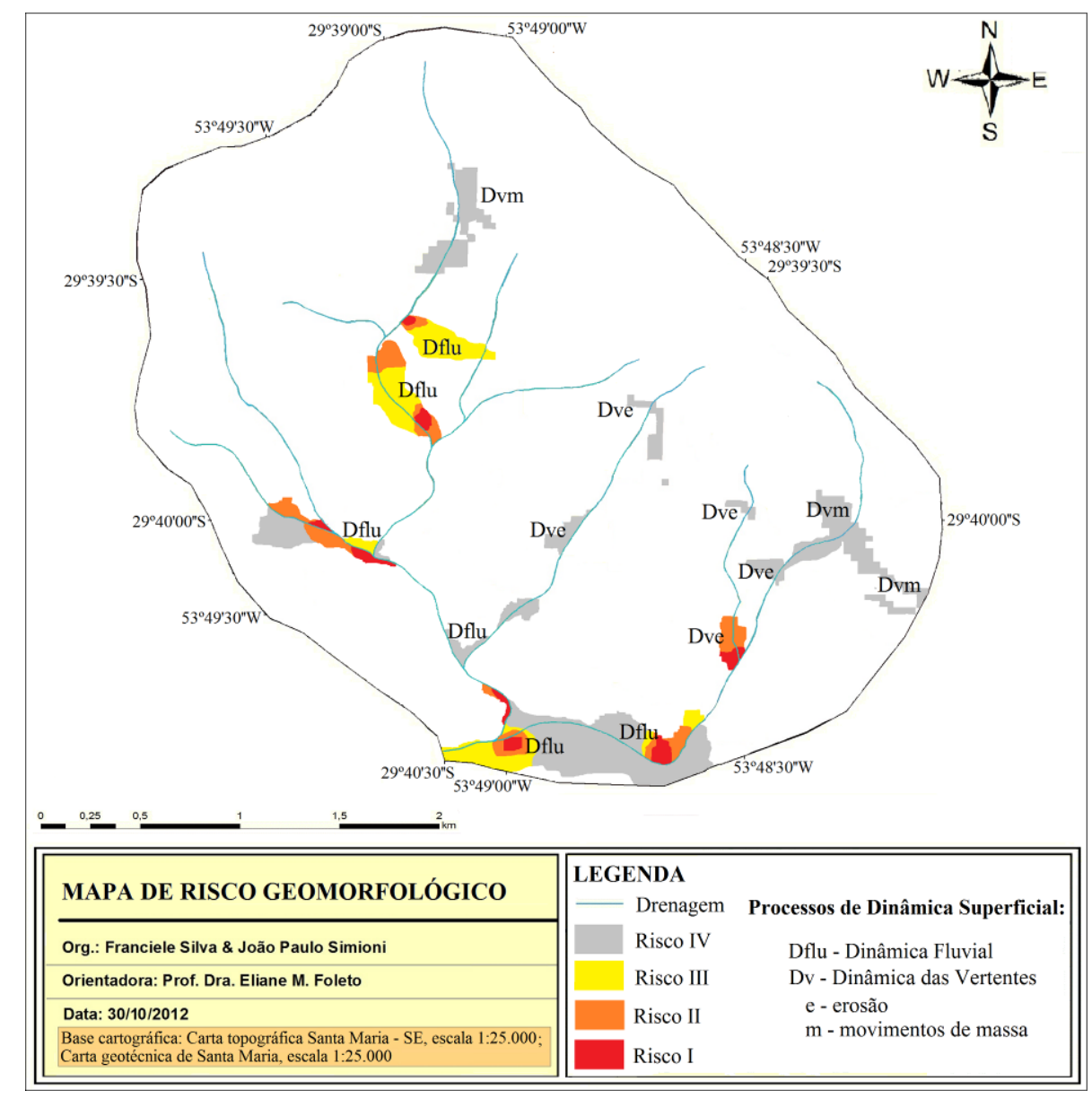

Figura 6: Mapa das áreas de risco geomorfológico da microbacia hidrográfica Chácara das Flores. 


\section{a aumentar.}

Outro subproduto da intensa modificação feita no espaço são as alterações que afetam a rede de drenagem e as áreas mais planas do relevo, dando origem às áreas de risco geomorfológico associadas à dinâmica fluvial, estas estão relacionadas com as áreas do relevo que se localizam muito próximas aos cursos fluviais e/ou áreas muito planas, onde encontramos tanto os processos de erosão das margens como também os processos de inundações/alagamentos.

Na confluência dos canais que formam a microbacia, são comuns os eventos que causam inundações, atingindo as residências ali localizadas, estas por apresentarem um baixo padrão urbano e alta densidade habitacional neste ponto, e estando localizadas em área susceptível, onde já foram registrados eventos/acidentes, fazem com que esta área possua risco iminente face aos processos da dinâmica fluvial, notadamente as inundações, essa realidade pode ser observada através da figura 7 .

Outro ponto a se destacar é próximo ao barramento, já nas áreas mais elevadas da microbacia. Apesar de neste local o canal não possuir grandes modificações, as habitações estão localizadas muito próximas às margens, possuindo um baixo padrão função urbana e tendo a ocorrência de eventos já registrados, além de estarem sobre áreas com declividade inferior a $2 \%$, ou seja, susceptíveis. Outro agravante do local, a se destacar, são as ruas e travessas que, na maioria das vezes, terminam junto ao canal principal, colaborando com o depósito de sedimentos dentro do canal. Este setor da microbacia foi considerado como sendo de risco iminente, junto ao canal, pela alta susceptibilidade natural, associada a uma grande vulnerabilidade do sistema social, representado pela população de baixa renda que, durante a evolução do espaço urbano, ficou condicionada a habitar estes locais.

Através do mapeamento das áreas de risco geomorfológico na microbacia, podemos quantificar que 18\% da área total da microbacia estão em situação de risco. A espacialização dessas áreas é dispersa e, com base no mapa, pode-se perceber que o predomínio é de áreas com risco a processos de dinâmica fluvial.

\section{Conclusões}

A interpretação dos processos geomorfológicos causadores de risco na microbacia hidrográfica Chácara das Flores, e seu zoneamento e hierarquização, são de fundamental importância para qualquer atividade, de planejamento ambiental e urbano democrático, que contemple a cidade como um todo, sua constituição material e o substrato onde esta se desenvolveu, as características geológicas e principalmente do relevo.

As áreas aqui analisadas, onde os riscos se manifestam para a sociedade, constituem muito mais do que uma representação espacial, que neste trabalho teve por finalidade cartografar os riscos, constitui-se na verdade de lugares que são criados ao longo da evolução social da cidade. Estas pessoas possuem uma identidade com estes lugares, mesmo porque várias destas áreas de risco têm uma idade superior a 20 anos de ocupação, tempo suficiente para manter relações muito profundas no

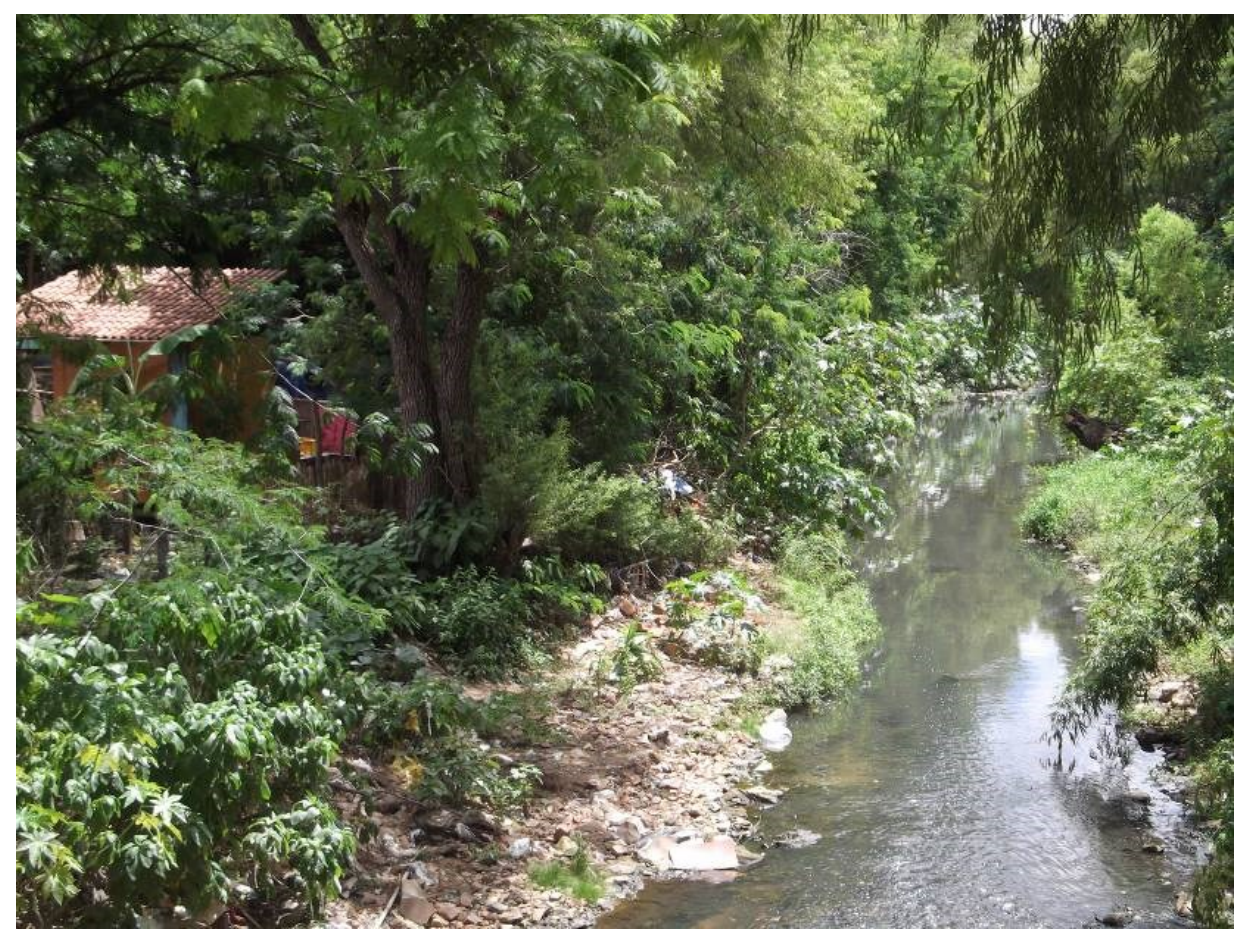

Figura 7: Moradia em situação de risco iminente, próximo à confluência dos canais.

Fonte: trabalho de campo. 
ambiente onde se vive.

Todavia, destaca-se que medidas preventivas, de controle ou de mitigação de situações como as descritas, são menos onerosas e mais eficientes na prevenção de tragédias. Embora inevitáveis, esses eventos são previsíveis. Nesse cenário, a maior conscientização e responsabilidade da população e dos poderes públicos se mostram como medida de adaptação inadiável.

\section{Referências}

AMARAL, C. P. Mapeamento Geológico-Geotécnico da Baixada de Sepetiba e Maciços Circunvizinhos - Parte Sul da Folha de Sta. Cruz. 1988. 130p. Dissertação de Mestrado (Instituto de Geociências) - Universidade Federal do Rio de Janeiro, Rio de Janeiro, 1988.

CASTRO, A. L. C de. Glossário de defesa civil: estudos de riscos e medicina de desastres. $5^{\text {a }}$ Edição. Secretaria Nacional de Defesa Civil SEDEC, 1998.

CERRI, L. E. S. Análise de riscos geológicos em planos de preventivos de defesa civil. In: IPT - Curso de geologia de engenharia aplicada a problemas ambientais. São Paulo, DIGEM/AGAMA.

EGLER, C. A. G. Risco Ambiental como critério de Gestão do Território: Uma aplicação à zona costeira brasileira. Território. Rio De Janeiro: LAGET, UFRJ. Vol. 1, n 1/ Jul/Dez. 1996.

JULIÃO, R. P.; NERY, F.; RIBEIRO, J. L.; BRANCO, M. C.; ZÊZZERE, J. L. Guia Metodológico para a Produção de Cartografia Municipal de Risco e para Criação de Sistemas de Informação Geográfica (SIG) de base municipal. 2009.

MACIEL FILHO, C. L. Carta Geotécnica de Santa Maria. Santa Maria: Imprensa Universitária UFSM, 1990. 21p.

OLIVEIRA, E. L. A. Áreas de risco geomorfológico na Bacia do Arroio Cadena, Santa Maria/ RS: zoneamento e hierarquização. 2004. Dissertação de Mestrado em Geociências Universidade Federal do Rio Grande do Sul, Porto Alegre: RS, 2004.

OLIVEIRA, E. L. A. ET AL. Metodologia utilizada para o mapeamento de áreas de risco geomorfológico: bacia hidrográfica do Arroio Cadena, Santa Maria - RS. In: SIMPÓSIO BRASILEIRO DE DESASTRES NATURAIS, 1., 2004. Anais... Florianópolis: GEDN: UFSC, 2004. p. 248 261 (CD - ROM). 